\title{
Risk Factors for Esophageal Cancer among Adults Aged 40 Years and Above in Sebei Region, Eastern Uganda
}

\author{
Article by Sabila Nelson ${ }^{1}$, Ndungutse David ${ }^{2}$, Kiiza Stephen ${ }^{3}$, Ddamulira Christopher ${ }^{4}$ \\ ${ }^{1}$ MPH, PhD Public Health Student, Texila American University \\ ${ }^{2}$ Professor, Dean of Public Health, St. Augustine international University, Kampala \\ ${ }^{3} \mathrm{PhD}$, Lecturer Graduate School, Bugema University, Kampala \\ ${ }^{4}$ MPH, PhD candidate, Lecturer School of Public Health, Bugema University, Kampala \\ E-mail:sabila840@gmail.com ${ }^{1}$,dndungutse@saiu.ac.ug ${ }^{2}$ sskiiza2011@gmail.com ${ }^{3}$, \\ chris_ddamulia@yahoo.co.uk $k^{4}$
}

\begin{abstract}
The study conducted in Sebei sub- region, Eastern Uganda aimed at assessing the risk factors for esophageal cancer among adults aged 40 years and above in Sebei region and to share the findings with the relevant stakeholders for effective management and control strategies. Methodology: The study employed a descriptive, un- matched case control design using quantitative and qualitative approach. 138 respondents were sampled from patients who were both esophageal cancer cases and non-cases (controls). Data was collected using face to face administered pretested questionnaire. Descriptive and inferential (chi- square and logistic linear regression) was applied to analyse the socio- demographic and economic, behavioural, environmental and medical factors of the respondents. Findings: The study found out that only; alcohol consumption (AOR: 9.95 95\%, CI: 2.59-36.08), $p=0.001$, tobacco use (AOR: $15.3795 \%, C I: 3.40-64.00) p=0.00$ and H. Pylori infection (AOR: 7.91 95\%, CI: 2.02-27.77), $p=0.001$ were significant risk factors. Other factors in the study were not significant risk factors ( $p>0.05)$. Conclusion: The study concluded that behavioural and medical factors were significant risk factors for esophageal cancer and that the lifestyle of adults aged 40 years and above had a significant impact on their esophageal cancer status. Recommendations: Cessation from alcohol consumption and tobacco use coupled with early testing and prompt treatment of $H$. Pylori infection can help avert the occurrence of esophageal cancer in the region.
\end{abstract}

Keywords: Risk Factors, Esophageal Cancer, Adults.

\section{Introduction}

Esophageal cancer is one of the most prevalent cancers Worldwide; it is extremely aggressive in nature and has a poor survival rate of only 15- 25\%, (Pennathur et al., 2013). It is the sixth leading cause of cancer-related mortality and the eighth most common cancer in the world (Zhang, 2013). In 2012, esophageal cancer affected more than 450000 people globally and the incidence is projected to increase rapidly (Pennathur et al., 2013).

There are two main histo- pathological subtypes: Squamous cell carcinoma (SCC), and esophageal adenocarcinoma (OADC), SCC is the predominant histological subtype worldwide. While adenocarcinoma is mainly a disease of developed countries, squamous cell carcinoma (SCC) is more common in developing countries (Melhado, et al., 2010). SCC is a result of abnormal growth of the squamous epithelial cells (hyperplasia) or total disappearance (dysplasia) while adenocarcinoma arises from undesired transformation of tissues that replace the squamous epithelium (metaplasia) (Blot, 1991).

Countries such as Turkey, Iran, and Kazakhstan, as well as northern and central China, with an estimated esophageal squamous carcinoma rate of more than 100 cases/100,000 people per year have been named "Asian esophageal cancer belt". Another area with a high incidence of squamous cell carcinoma is south eastern Africa, Nevertheless, squamous carcinoma remains the most common subtype in American black males; however, adenocarcinoma is one of the few cancers that contribute to increased mortality from cancer among all American men and other developed countries like; United Kingdom, France, Australia and Finland (Shamsifar et al., 2015). 
Several factors have been identified as risk factors for esophageal cancer. For instance, a research by Wei et al., (2011) found out that socio-demographic, behavioural, socio-economic, environmental and medical factors such as age, gender, level of education, family history, marital status, Occupation, smoking, hot tea drinking, red meat consumption, poor oral health, low intake of fresh fruit and vegetables, low socioeconomic status were risk factors. Others include Helicobacter Pylori (H. Pyori) and Human Papilloma Virus (HPV) infection. It was further discovered that Barrett's oesophagus caused by gastro-esophageal reflux disease (GERD) is clearly recognized as a risk factor for esophageal cancer (Gibson, 2017).

Difficulty in swallowing (dysphagia) remains the only factor useful for identifying patients at increased risk of developing esophageal adenocarcinoma in clinical practice (Zhang, 2013; Talukhtar et al., 2013; Torre et al., 2015).Other clinical presentations include; weight loss, and heartburn unresponsive to medical treatment, as well as signs of blood loss; however, an increasing number of essentially asymptomatic cases are being discovered as part of screening and surveillance endoscopy.

In Africa, about 27,500 new cancer cases and 25,200 deaths from esophageal cancer were estimated to have occurred in 2012, 89\% of these in Sub-Saharan Africa. It is more common in males than females and incidence rates are particularly high in East Africa the East Cape Province (former Transkei) area of South Africa. Almost all of the esophageal cancers in these high risk areas are squamous cell carcinomas. The reasons for the high burden of esophageal cancers in several parts of Eastern Africa and Southern Africa are not fully understood (Par kin, et al., 2012).

The WHO Country profile for Uganda (WHO, 2014) indicates that 18,100 people died of esophageal cancer in 2014, out of whom, 9,100 were males and 9,000 were females. The report ranked esophageal cancer in the country the second cause of all cancer related deaths among males and fourth among females. Hospital records from Bukwo and Kapchorwa hospitals show an increasing rate of esophageal cancer among the elderly aged 40 years and above who attend medical services in these hospitals from an estimated 3 percent in 2014 to about 10 percent in 2016.

Esophageal cancer is one of the biggest health problems among the elderly aged 40 years and above in Sebei region. In 2016, over $10 \%$ of patients aged 40 years and above admitted to the two district hospitals of Bukwo and Kapchorwa had esophageal cancer. Records also indicate that esophageal cancer prevalence significantly rose from about $2 \%$ in 2012 to $10 \%$ in 2016 (HMIS, 201217). It is also apparent that esophageal cancer is the leading cause of cancer related mortality in the three districts served by the Hospitals. In comparison with the national prevalence where esophageal cancer is ranked the second cause of mortality from all cancer-related deaths (WHO, 2014), the increasing trends of esophageal cancer prevalence in Sebei region is troubling and to address it appropriately, the respective district health offices and the Ministry of Health require adequate information on local risk factors.

Furthermore, efforts that have been put in place to address this seemingly rising problem have not been clearly documented or assessed. As a result, therefore, little is known about the most probable risk factors and prevalence rates of esophageal cancer among the elderly people in the three districts. The research therefore sought to narrow the knowledge gap.

The departments of health in the respective districts of Sebei region, together with the ministry of health, will utilize the findings to design appropriate management and preventive measures against oesophageal cancer. Enable the Communities of Bukwo, Kapchorwa and Kween Districts have increased awareness on the risk factors for oesophageal cancer which will in turn help them to adopt healthy life styles necessary for prolonged and quality lives. The policy making organs such as Parliament and Lower Local Government Councils can use the information from these findings to legislate for healthy living. Scholars will benefit from the findings of this study as it will provide reference materials for future studies in same or similar fields.

The study was limited by the fact that the oesophageal cancer cases were not available in the Hospitals but in the communities, this is because the two Hospitals did not have screening services but made clinical diagnosis there after refer suspected cases to Mulago or Kenya for confirmatory tests though they provide palliative care for services for the already confirmed cases. The researcher overcame this challenge by acquiring the list of cases from the Hospitals' records and recruited research assistants who knew the residences of the cases to collect the data.

Evidence from earlier studies recommend modification of lifestyle through behaviour change as the best means to reduce esophageal cancer incidences (Heath et al., 2000). This includes changing 
addictive behaviours like tobacco and alcohol use. Behaviour change requires a cautious approach as it involves the deep interrelation of all three factors (biological, psychological, social) that lead to a given outcome, each component on its own is insufficient to lead definitively to health or illness (Engel, 1980). Although best outcomes are associated with early disease diagnosis, it is often difficult and uncommon to do so in these rural areas of Sebei region in eastern Uganda.

\section{Methodology}

This section covers the research design used in the study, the location, , study population, sample size, sampling procedures, research instruments/tools, validity and reliability of instruments, data collection procedure and data analysis.

\section{Research design}

Esophageal cancer is a rare disease, for that reason, the study adopted a descriptive un-matched other than a matched case-control study design in which controls were enrolled without regard to the number or characteristics of the cases; the number of controls was not necessarily equal the number of cases. A mixed exploratory approach was used that combined both quantitative and qualitative methods. Cases were detected from disease registries where they had been confirmed through screening. The controls where be selected randomly from both the in and out patients available in the two Hospitals during the study time and were selected without regard to their exposure status (for example, exposed/non-exposed). The study was both descriptive and correlational. The respondents were enrolled basing on their current disease status, previous exposure status was subsequently determined for each case and control.

\section{Locale of the study}

The study was carried out in Sebei region and specifically, Bukwo and Kapchorwa District hospitals. Bukwo Hospital is located in Bukwo Town Council which is the headquarters of Bukwo District and serves mainly the population in Bukwo District. Kapchorwa Hospital is located in Kapchorwa Town Council which is the headquarters of Kapchorwa District and is actually a regional referral Hospital serving mainly three Districts namely, Bukwo, Kween and Kapchorwa. These Districts are located in Eastern Uganda, a range of land between 270 and $340 \mathrm{~km}$ from Kampala City. The three Districts have a combined population of 286,209 people according to the Uganda Population and Housing Census (UPHC, 2014). Figure 1 in the appendix is the map of the study location.

\section{Target population}

The target population included all the adults aged 40 years and above in the three districts of Sebei region comprised of; Bukwo, Kween and Kapchorwa. The Uganda National Population and Housing conducted in 2014 put the number of the adults aged 40 years and above population at 41,345 from all the three districts.

\section{Study population}

The adults in the age category of 40 years and above from Sebei region and attended medical services in Bukwo and Kapchorwa District Hospitals at the time of study comprised the study population. Any individual below the age of 40 years or from outside the three districts comprising Sebei region were excluded from the study.

\section{Sample size and procedure}

A sample size of 138 respondents was used for the study, being an unmatched case control study, the number of cases was 39 while the controls were 99.

The sample size was determined using the formula of Cochran (1977):

$\mathrm{N}=\mathrm{t}^{2} \cdot \mathrm{pq} / \mathrm{d}^{2}$. Where: $\mathrm{t}=$ value of $95 \%$ confidence level will be used, 0.025 in each tail $=1.96$,

$\mathrm{p}=$ estimated proportion of the population having esophageal cancer as seen from the Hospital records $=0.1, \mathrm{q}=1-\mathrm{p}$ (estimated proportion of population without esophageal cancer) $=0.9, \mathrm{~d}=$ 
DOI: 10.21522/TIJPH.2013.SE.19.01.Art009

ISSN: $2520-3134$

acceptable margin of error $=0.05$. Therefore, substituting in the above formula,

$\mathrm{n}=\frac{(1.96) 2(0.1)(0.9)}{(0.05) 2}=138$

During the study, a list of cases was obtained from the disease registries of the two Hospitals while a purposive sampling method was used to select the controls from all the available clinics within the Hospitals, all individuals aged 40 years and above attending medical services in Bukwo and Kapchorwa District Hospitals at the time of the study were enrolled until the required sample size was attained. Excluded from the study were those who did not consent. Both in-patient and out-patient service attendees were enrolled for the study. 11 cases and 28 controls which represented 0.28 or $28 \%$ were interviewed from Bukwo District Hospital while 28 cases and 79 controls which represented 0.72 or $72 \%$ of the total sample size were interviewed from Kapchorwa referral Hospital.

The key informants were sampled purposively and the health workers with sufficient knowledge and experience in handling cases of esophageal cancer in the two Hospitals of Bukwo and Kapchorwa were targeted for the study.

\section{Instruments/ research tools}

The study employed two (02) instruments, they are questionnaires and key informant interview guides.

\section{Questionnaire}

The interviewer- administered questionnaire was used as the main instrument and was designed to attract suitable responses from the selected respondents. These responses were pre-coded as much as possible. The data on the questionnaire was collected by interview and has six sections comprising the socio demographic information, main variables are categorized under socio economic, behavioural, medical, and environmental factors. They include age, gender, education level, occupation, tobacco use, economic status, family history of esophageal cancer, alcohol consumption, physical activity, consumption of vegetables and fruits, taking of hot drinks, history of HPV infection, history of $H$. Pylori infection and dysphagia. The other section shows the disease status, whether sick or not. Also included are suggestions and recommendations for prevention and management of esophageal cancer.

\section{Key informant interview guide}

The second instrument used in addition to the questionnaire was the key informant interview guide administered to the health workers at the two district hospitals. Specifically, a structured interview guide consisting of open-ended questions relevant to the research objectives and utilized in the collection of qualitative data. The key informant guide is important because it enabled collection of rich data given the freedom of the respondents to air out their views.

\section{Quality assurance}

In the study, quality control measures were undertaken to ensure the findings of the study met acceptable standards. These measures included validity and reliability checks.

\section{Validity}

Information from the pre-test was used to adjust the instruments to improve their validity and reliability. To establish the Content Validity Index (CVI). The following formula was used;

$\mathrm{CVI}=\mathrm{K} / \mathrm{N}$. Whereby; $\mathrm{K}=$ total number of items in the questionnaire declared valid by the panel of supervisors and approved by the Institutional Research Committee (IRC) $=46, \mathrm{~N}=$ total number of items in the questionnaire $=49$. In order for the research instruments to be valid, the CVI should be $\geq$ 0.7 .

Therefore; 46/49=0.94. The Content Validity Index (CVI) was found to be $=0.94$. The research instruments were therefore declared valid.

\section{Reliability}

To assess the reliability of the instruments, the researcher pre- tested it on 20 participants who were not part of the actual study sample. The instruments pre- tested in Kapkwoloswo Health Center Three 
in Bukwo district which was randomly selected by writing each name of the Eleven HCIII's from the region on separate pieces of paper. The pieces of paper were folded, put into a box and shaken, one was therefore picked by the researcher and used for the pre-test. The random technique was chosen in order that each of the existing HCIII's had equal chances of being picked for the pilot study thereby minimizing selection bias. The respondents here had similar characteristics as the actual study respondents.

\section{Ethical approval}

The technical approval to conduct this study was obtained from Mulago Hospital Research and Ethics Committee (MHREC). All respondents who participated provided written consent, those who did not were left out of the study.

\section{Data collection procedure}

Secondary data from hospital records or disease registries was used to identify the proven esophageal cancer cases among patients aged 40 years and above hailing from Sebei region and seeking medical services at Bukwo and Kapchorwa Hospitals. The research instruments and tools were first pre tested and validated prior to the actual data collection. The data collection involved individual face to face interviews with the selected respondents and key informants using the designed questionnaires and guides. Responses were recorded accordingly for each interview conducted.

\section{Data analysis}

The collected data was entered, edited and cleaned. Some of the uncoded responses were postcoded. The cleaned dataset was analysed using SPSS version 20 because of its ease of use and the superiority in producing tables. Univariate analysis was used to generate descriptive statistics for objectives one to four such as frequencies and percentages. Chi-square tests were used to establish relationships between different categorical variables such as; gender, education level, tobacco use, alcohol use, exposure to aflatoxins, pesticides, fertilizers, family history of $H$. Pylori and HPV infection and dysphagia were the independent variables while esophageal cancer status was the dependent variable.

Multivariate analysis was used for objective five, all the variables that were found to be significantly associated with esophageal cancer; with a p-value of $\leq 0.05$ were filled into a logistical regression model; $\log$ it $(y)=a+b, X_{1}+B_{2} X_{2+} B_{3} X_{3}+\ldots \ldots \ldots B_{k} X_{k}$.

Where; $\mathrm{B}_{1} \mathrm{X}_{1} \ldots \ldots \mathrm{X}_{\mathrm{k}}$ are independent variables being tested in the model and $\mathrm{y}$ is the dependent variable. The predictor variables were; age gender, education level, marital status, alcohol use, tobacco use, exposure to aflatoxins, pesticides, fertilizers, physical inactivity, family history of esophageal cancer, history $H$. Pylori and HPV infection and dysphagia while the outcome variable was esophageal cancer status. The results are presented using tables, charts and text wherever appropriate.

The data obtained from key informants was transcribed into topics and subsequently to themes which were presented as texts, others were also quoted verbatim.

\section{Results and discussion}

This chapter covered descriptive presentation of respondents' characteristics and inferential statistics for hypothetical validation between variables. Discussion of results was made and meanings attached to the findings. There were 138 respondents all together; 39 esophageal cancer cases and 99 controls. Ten key informants were also interviewed including the District Health Officers, the Medical Superintendents Hospitals, Clinical Officers and senior nurses.

\section{Risk factors for esophageal cancer}

To determine the risk factors for esophageal cancer among adults aged 40 years and above attending medical services at Bukwo and Kapchorwa Hospitals. The socio- demographic, behavioural, environmental and medical related factors were subjected to chi square statistical analysis to determine the significance of the relationship. Further linear logistic (bivariate and multivariate) regression analysis was done and variables with significant relationships are covered, as shown in Table 1 appended. 
In reference to Table 1 , factors that were identified under bivariate analysis were; age, oral hygiene, alcohol consumption, tobacco use, fertilizer use, H. Pylori infection, Pesticide exposure, exposure to aflatoxins. These factors showed significant association between cases and controls with the development of esophageal cancer.

In multivariate logistical linear regression analysis, only alcohol consumption, tobacco use and $H$. Pylori infection were risk factors for esophageal cancer after control of confounding variables.

\section{Age}

Under socio- demographic factors at bivariate level of analysis, age of adults had a significant bearing on the development of esophageal cancer among adults. Using the age group of 40-49 years as reference category, there is a high likelihood of one developing esophageal cancer as one gets older. Within the age of 50-59 years the odds ratio is (COR: $9.10095 \%$ CI, CI: 2.774, 29.853) and the age between 60- 69 with (COR: 5.014 95\%, CI: 1.555, 16.168).

However, controlling for other factors in the multivariate analysis, age was not a significant factor. Although some earlier findings indicate a peak age of over 50 years in $80 \%$ of esophageal cancer patients (Wei et al., 2011). Findings of this study are in agreement with the findings of Heiko et al.,2012) who while studying the risk factors for the development of esophageal cancer in America concluded that age was not a risk factor.

\section{Alcohol consumption}

As seen from Table 10, alcohol consumption as one of the behavioural factors showed a significant risk for the development of esophageal cancer at both bivariate and multivariate level of analyses. Bivariate analysis showed that the alcohol users were about 14 times more likely to develop esophageal cancer than none alcohol users (COR: 13.96 95\%, CI: 5.268, 36.924) controlling for other factors in multivariate analysis, alcohol uses is a significant risk factor (AOR: 9.947 95\%, CI: 2.592, 36.08) with a p- value of 0.001 .

According to Kleinber et al., (2014), alcohol (ethanol) is converted into a toxic chemical called acetaldehyde which irritates and inflames the lining of the esophagus, this may cause esophageal cancer by damaging the DNA in cells that line the inside of the esophagus and stopping our cells from repairing this damage. DNA is the chemical in each of our cells that makes up our genes, the instructions for how our cells function (Kleinber et al., 2014). We usually look like our parents because they are the source of our DNA. However, DNA affects more than how we look. Some genes control when cells grow, divide into new cells, and die. Genes that help cells grow, divide, and stay alive are called oncogenes. Genes that slow down cell division or make cells die at the right time are called tumor suppressor genes. Cancers can be caused by DNA changes that turn on oncogenes or turn off tumor suppressor genes (Shaheen et al., 2016).

Alcohol also acts as a catalyst for assimilation of carcinogenic traces into the human body, for example, alcohol makes it easier for the mouth and throat to absorb the cancer-causing chemicals in tobacco including nicotine (Kleinber et al., 2014). The study findings are consistent with the findings of a 2011 meta- analysis of 4 cohort and 8 case- control studies conducted between 1990-2010 in Japan by Yingsong et al.,(2013) which revealed that alcohol drinkers had at least a 3.3 fold increased risk of developing esophageal cancer as compared with none drinkers.

\section{Tobacco use}

The findings as shown in Table 1 indicate that tobacco use was a statistically significant risk factor in the development of esophageal cancer. Bivariate analysis revealed that tobacco users were about 25 times more likely to develop cancer of the oesophagus than the non- users (COR: 24.800 95\%, CI: $8.690,70.708)$. This significance persisted even after the adjustment at the multivariate analysis level (AOR: 15.37 95\%, CI: 3.692, 64.00) with a p- value of 0.000 .

Cigarettes, cigars, and pipe tobacco are made from dried tobacco leaves. Other substances are added for flavor and to make smoking more pleasant. The smoke from these products is a complex mixture of chemicals produced by burning tobacco and its additives. Tobacco smoke is made up of several chemicals believed to cause cancer (Posnaret et al., 2015). These cancer-causing chemicals are referred to as carcinogens. Some of the chemicals found in tobacco smoke include: Nicotine (the addictive drug that produces the effect people are looking for and one of the harshest chemicals in 
tobacco smoke), Hydrogen cyanide, Formaldehyde, Lead, Arsenic, Ammonia, Radioactive elements, such as uranium, Benzene, Carbon monoxide, Nitrosamines, Polycyclic aromatic hydrocarbons (PAHs) among others(Shaheem et al.,2016).

The study findings are in agreement with other research findings by; Talukhar et al., (2013), Zhang, (2013) and Loppes and Fergundes, (2016) all of which revealed significant a relationship between tobacco use and esophageal cancer development.

\section{Fertilizer use}

According to Table 1, tests conducted for fertilizer use and non-use at bivariate level showed that fertilizer non- users are 3 times less likely to develop esophageal cancer compared to the users (COR: $0.30495 \%$, CI: $0.140,0.662$ ) (AOR : 0.594 95\%, CI: $0.163-2.05$ ) and with a p- value of 0.002 , the significance disappeared during multivariate analysis. This could be explained by the quantities and active elements in different fertilizers used by the respondents. The odds ratios at $95 \%$ confidence interval in the study suggest fertilizer use as a protective factor against esophageal cancer.

The findings could not agree with those of Nan et al., (2012) who focused on the association of three nitrogen compounds in drinking water, namely, nitrates, nitrites, and ammonia, all of which are derived mainly from domestic garbage and agricultural fertilizer with esophageal carcinoma in Shxian China which revealed no significant risk of esophageal cancer with high concentrations of the said nitrogenous compounds hence need for further studies.

\section{Exposure to aflatoxins}

According to Table 1, when exposure to aflatoxins was subjected to bivariate analysis, those respondents who had not been exposed to aflatoxins were 5 times less likely develop esophageal cancer as compared to those exposed (COR: 0.230 95\%, CI: 0.099, 0.536), (AOR: 1.12 95\%, CI: $0.35-4.10)$ with a p- value of 0.000 , this significant association vanished at multivariate analysis level which could possibly be explained by the short period of exposure and when harvest is done under moist conditions. The low odds ratio at $95 \%$ confidence level in the study suggest that exposure to aflatoxins is protective against esophageal cancer.

Although research findings by International Agency for Research on Cancer show that aflatoxins are carcinogenic to human beings (IARC, 2012), another agricultural health study by the American National Cancer Institute also confirmed the carcinogenic nature of aflatoxins but did not identify it as a risk factor for esophageal instead other cancers such as Liver cancer, this suggests a need for more research.

\section{Pesticide use}

Table 1 shows that use of pesticides by the respondents was a risk factor for esophageal cancer development at bivariate and not at multivariate level of analysis. At bivariate level, those respondents who were not exposed to pesticides were 3 times less likely to develop esophageal cancer than those who were exposed (COR: 0.272 95\%, CI: 0.125, 0.590), (AOR: 0.83 95\%, CI: 0.23- 3.10) with a pvalue of 0.001 .

The odds ratio from the study suggests that pesticides are protective against esophageal cancer. The study findings are consistent with those of International Agency for Research on Cancer (IARC) study in a farming area in East Nebraska between 1988 and 1993 where no risk for esophageal cancer was established with pesticide use (Zahm et al., 1990; Lee et al., 2004).

\section{Helicobacter pylori (H. Pylori) infection}

The tests on the significance of $H$. Pylori infection showed that those exposed had a 4 times higher odds of developing esophageal cancer compared to those not exposed to H. Pylori at bivariate level of analysis and 8 times higher at multivariate analysis level (COR: $3.9095 \%$, CI: 1.772, 8.627) and (AOR: $7.9195 \%$, CI: 2.021, 27.768) with a p- value of 0.001 .

Ye et al., (2004) first reported that esophageal squamous cell carcinoma was positively associated with both serological evidence of atrophic gastritis and with $\mathrm{H}$ pylori CagA-positive infection in the Swedish population. A similar association has recently been observed in Japan (Lijimaet al., 2006). Therefore, the study findings are in agreement with the findings of Handa et al., (2011) that $\mathrm{H}$. Pylori 
DOI: 10.21522/TIJPH.2013.SE.19.01.Art009

ISSN: 2520-3134

is a major causative agent for esophageal cancer and other various benign and malignant gastrointestinal tract diseases.

\section{Qualitative data findings}

During the study, 10 key informants who were medical professionals working in both Bukwo and Kapchorwa Hospitals and knowledgeable on issues of esophageal cancer were interviewed and the results are analysed in Table 2 in the appendix.

As seen from Table 2, tobacco use and alcohol consumption were rated by the key informants as highly significant risk factors for esophageal cancer among adults aged 40 years and above who were attending medical services at Bukwo and Kapchorwa Hospitals. These views are in agreement with the findings from the quantitative study findings which identified tobacco use and alcohol consumption as significant risk factors.

Results from the qualitative study ranked H. Pylori infection as one of the least important risk factors for esophageal cancer, this contradicts with the findings from the quantitative study which indicated $\mathrm{H}$. Pylori to be a significant risk factor. The inconsistence could a result of the fact that qualitative analysis does not involve rigorous testing as in quantitative and is based on the perceptions of key informants on the subject matter.

Whereas the key informants ranked exposure to aflatoxins, pesticide use and gender of patients as important risk factors, the findings from the quantitative study show these factors to be protective for esophageal cancer after subjecting the data to rigorous analysis; descriptive, bivariate and finally multivariate levels of analysis.

\section{Conclusion}

The study found out three final significant risk factors for esophageal cancer among adults aged 40 years and above from Sebei region attending medical services at Bukwo and Kapchorwa Hospitals. They are; alcohol consumption, tobacco use and H. Pylori.

The rest of the factors; age, gender, Occupation, marital status, Human Papilloma Virus (HPV), income levels, level of education, dysphagia, exposure to aflatoxins, fertilizer use, pesticide use, eating vegetables and fruits, physical activity were found to be protective factors for esophageal cancer among the study respondents.

The interaction of the biological, psychological and social aspects as theorized by George L. Engel in 1980 could not clearly explain the outcome of this study unless further research links the Bio psychosocial aspects to the consumption of alcohol, tobacco use and $\mathrm{H}$. Pylori infection being the identified risk factors esophageal cancer among the study subjects.

\section{References}

[1]. Altieri, A., La Vecchia, C., Negri, E. (2003). Fluid intake and risk of bladder and other cancers. Eur J ClinNutr57 (Suppl 2): S59-S68.

[2]. Alavanja, M.C \& Bonner, M.R. (2012). Occupational pesticide exposures and cancer risk: a review. J. Toxicol. Environ. Health B Crit. Rev. 15 (4), 238-263.

[3]. Bagnardi, V., Rota, M., Botteri, E., Tramacere, I., Islami, F., Fedirko, V, et al, (2013). Light alcohol drinking and cancer: a meta-analysis. Annals of Oncology 24: 301-308, 2013. doi:10.1093/annonc/mds337. Published online 21 August 2012

[4]. Baldi, I., Lebailly, P. (2007). Cancers and pesticides. Rev. Prat. 57 (11 Suppl.), 40-44.

[5]. Blot, W. J., Devesa, S. S., Kneller, R. W., et al. (1991). Rising incidence of Adenocarcinoma of the oesophagus and gastric cardia. JAMA 265.1297-9.

[6]. Boffetta, P., Hashibe, M., La Vecchia, C et al., (2006). The burden of cancer attributable to alcohol drinking. Int J Cancer 2006; 119: 884-887.

[7]. Brusselaers N, Ljung R, Mattsson F., et al. (2013). Education level and survival after Esophageal cancer surgery: a prospective population-based cohort study BMJ Open; 3:e003754. doi: 10.1136/bmjopen-201300375 .

[8]. Chokunonga, E., Borok, M., Chirenje, Z., Nyakabau, A. and Parkin, D. (2013). Trends in the incidence of cancer in the black population of Harare, Zimbabwe 1991-2010. Int J Cancer.; 133:721-729. 
[9]. Dar, N. A., Islami, F., Bhat, G. A, Shah, I. A., Makhdoomi, M. A., Iqbal, B. (2013). Poor oral hygiene and risk of esophageal squamous cell carcinoma in Kashmir. Brittish Journal of Cancr 109. 1367-1372. Doi: 10. 1038/bcj. 213.437.

[10]. De Martel, C., Ferlay, J., Franceschi, S., Vignat, J., Bray, F., Forman, D., et al. (2008). Global burden of cancers attributable to infections in; a review and synthetic analysis. Lancet Oncol.

[11]. Engel G. L. (1980). "The clinical application of the biopsychosocial model". American Journal of Psychiatry 137 (5): 535-544. PMID 7369396. doi: 10.1176/ajp.137.5.535.

[12]. Gerson,L . B. (2009) "Endoscopic mucosal resection for early esophageal cancer- Replacement for oesophagectomy?" Gastroenterology, vol.136, no.1, pp.359-360.

[13]. Gibson M. (2017). Epidemiology, pathobiology, and clinical manifestations of Esophageal cancer. UpToDate Website. Updated February 10, 2017. Accessed April 08, 2017.

[14]. Guo, P. Z. L. Huang, P., Yu, K. Li. (2012). Trends in cancer mortality in China: an update. Ann Oncol; 23 (10): 2755-2762. doi: 10.1093/annonc/mds069.

[15]. Handa, O., Naito, Y., Yoshikawa, T. (2011). Redox biology and gastric carcinogenesis: the role of Helicobacter pylori. Redox Rep; 16: 1-7 [PMID: 21605492 DOI: 10.1179/174329211X1296 8219310756].

[16]. Heineman, E., F., Lijinsky, W., Lee, W. J., Markin, R. S., Weisenburger, D. D., Ward M H. “Agricultural pesticide use and adenocarcinomas of the stomach and oesophagus," Occupational and Environmental Medicine, vol.61, no.9, pp.743-749, 2004.

[17]. Herrera-Goepfert, R., Lizano, M., Akiba, S, et al (2009). Human papilloma virus and esophageal carcinoma in a Latin-American region. World J Gastroenterol, 15, 3142-7.

[18]. Hu, H.M, Kuo, C.H., Lee, C.H., Wu, I.C., Lee, K.W., Lee, J.M., Goan, Y.G, Chou, S.H, Kao, E.L, Wu, M.T., Wu, D.C. (2009). Polymorphism in COX-2 modifies the inverse association between Helicobacter pylori sero positivity and esophageal squamous cell carcinoma risk in Taiwan: a case control study. BMC Gastroenterol; 9: 37 (PMID: 19463183 DOI: 10.1186/1471-230X-9-37).

[19]. Islami, F, \& Kamangar, F. (2008). Helicobacter pylori and esophageal cancer risk: a meta- analysis. Cancer Prev Res (Phila); 1: 329-338 [PMID: 19138977 DOI: 10.1158/1940-6207. CAPR 08.

[20]. Jemal A, Siegel R, Xu J, Ward E. Cancer statistics, 2010. CA: A Cancer Journal for Clinicians 2010; 60(5):277-300.

[21]. Kipsengeret, K. K., Mbaria, J. M., Muchemi, G. M., Kitala, P. M, \& Laititia, W. K. (2016). Occupational exposure to pesticide and associated health problems in Kenya's floriculture industry. 1 (1). 1-10. Available at http://www.prudentjournals.org/PRJMMS.

[22]. Kirtika, P., Mwangi, A., Simeon, M., Radheka, P., Wakhisi, J. 2013. Esophageal Cancer, the Topmost Cancer at MTRH in the Rift Valley, Kenya, and Its Potential Risk Factors: Hindawi Publishing Corporation ISRN Oncology Volume, Article ID 503249, 9pages. Accessed on 13 ${ }^{\text {th }} / 03 / 2017$ from http://dx.doi.org/10.1155/2013/503249.

[23]. Koros, K. K., James, M., Mbaria., Gerald, M., Muchemi., Philiph, M., Kitala. \& Laititia, W. K. (2016) Occupational exposure to pesticide and associated health problems in Kenya's floriculture industry. Vol. 1 Issue 1, pp: (1-10), September. Accessed on $16^{\text {th }}$ march 2017: http://www. Prudentjournals.org/PRJMMS.

[24]. Lagergren, J., Gunnar, A., Mats, T., Sven, D., Erik, B., Juho, H. Marital Status, Education, and Income in Relation to the Risk of Esophageal and Gastric Cancer by Histological Type and Site. Cancer: 122.207- 12. Doi: 10. 1002/cnc29731.

[25]. Lambert, R.; Hainaut, P. (2007). Epidemiology of oesophago-gastric cancer. Best Pract. Res. Clin. Gastroenterol., 21, 921-945.

[26]. Iijima K, Koike T, Abe Y, Yamagishi H, Ara N, Asanuma K, et al. Gastric hyposecretion in esophageal squamous-cell carcinomas. Dig Dis Sci. 2010; 55:1349-55.

[27]. Maxwell, D., Parkin, B., Ferlay, J. and Jema, A. (2014). American Association for cancer Research. DOI: 10.1158/1055-9965.EPI-14-0281. Accessed from cebp.aacrjournals.org on $6^{\text {th }}$ February 2017.

[28]. Melhado, R E., Derek, A \& Tucker, O. (2010). The Changing Face of Esophageal Cancer Cancers, 2, 1379- 1404; doi: 10.3390/cancers2031379 ISSN 2072-6694 Accessed on www.mdpi.com/journal/cancers.

[29]. Mostafalou, S \& Abdollahi, M., 2012c. Current concerns on genotoxicity of pesticides. Int.J. Pharmacol. 8 (6), 473-474.

[30]. Paige, M., Kevin, D. S., Yu, Y. and Naimi T S. (2013). Alcohol-Attributable Cancer Deaths and Years of Potential Life Lost in the United States. American Journal of Public Health: Vol. 103, No. 4, pp. 641-648. Doi: 10.2105/AJPH.2012.301199.

[31]. Parkin, D.M. (2008). The role of cancer registries in cancer control. Int J ClinOncol; 13:102-11. 
DOI: 10.21522/TIJPH.2013.SE.19.01.Art009

ISSN: $2520-3134$

[32]. Soroush, S., Saba, S., Sadegh, R. and Mahin.A. (2012-2014). Study of Risk Factors for esophageal Cancer in Khorramabad City From. doi: 10.17795/jjcdc- 33229.

[33]. Stefani, D. E., Muñoz, N., Esteve, J., Vasallo, A., Victora, C.G., Teuchmann, S. (1990). Mate drinking, alcohol, tobacco, diet, and esophageal cancer in Uruguay. Cancer Res, 50: 426431.

[34]. Talukdar, F.R., Ghosh, S. K., Laskar, R.S., Mondal, R. (2013). Epigenetic, Genetic and Environmental Interactions in Esophageal Squamous Cell Carcinoma from Northeast India. PLoS ONE 8(4): e60996. doi: 10.1371/journal.pone.0060996.Editor: Zhihua Liu, Chinese Academy of Medical Sciences, China. Published online 2016 April 26.

[35]. Torre, L. A., Bray, F., Siegel, R. L., Ferlay, J., Lortet-Tieulent, J. and Jemal, A. (2015). Global cancer statistics, 2012. CA: A Cancer Journal for Clinicians, 65: 87-108. doi:10.3322/caac.21262.

[36]. Wei, M. M., Wei-Hui, Z., Zhi-Qiang, L. Epidemiologic Risk Factors for Esophageal Cancer Development. Asian Pacific J Cancer Prev, 12, 2461-2466.

[37]. Weichenthal, S., Moase, C., Chan, P., 2010. A review of pesticide exposure and Cancer incidence in the Agricultural Health Study cohort. Environ. Health Perspect. 118 (8), 1117-1125.

[38]. World Health Organization. (2010). Health system response and capacity: Policies, strategies and action Plans by country. Available from: http://apps.who.int/gho/data/node.main.A907? lang1/4en.

[39]. Wu, I.C., Wu, D.C., Yu, F.J., Wang, J.Y., Kuo, C.H., Yang, S.F, et al., (2009). Association between Helicobacter pylori sero positivity and digestive tract Cancers. World J Gastroenterol; 15: 5465-5471 (PMID: 19916178).

\section{Appendices}

\section{Appendix 1}

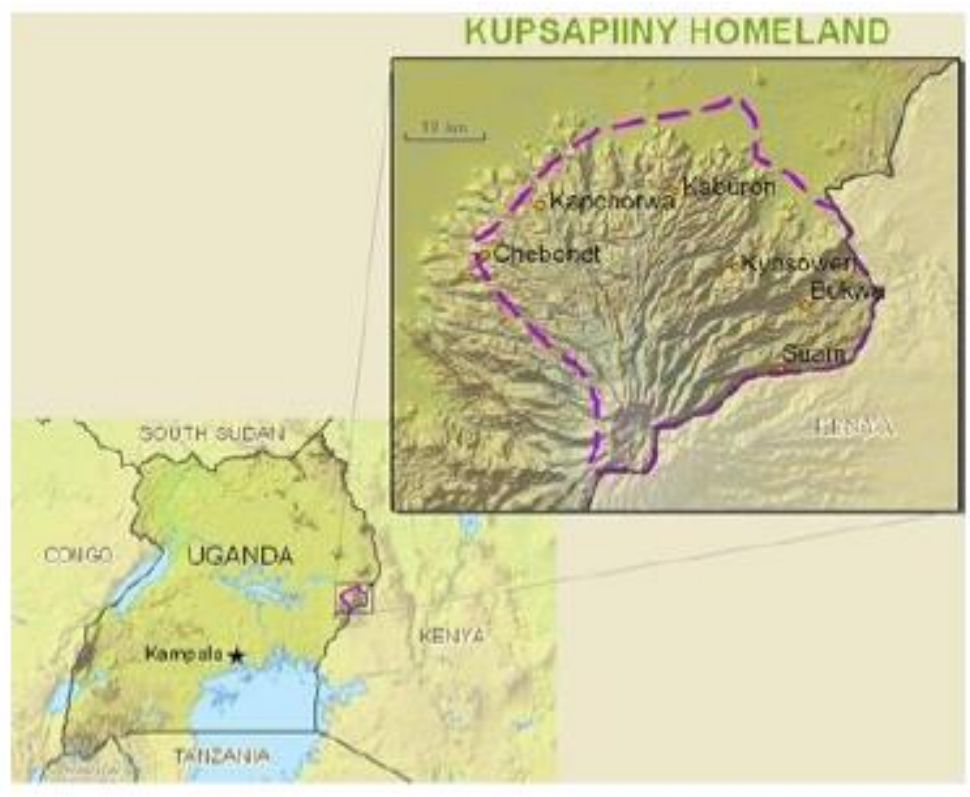

Figure 1. Map showing the main area covered by Bukwo and Kapchorwa Hospitals.

\section{Appendix 2}

Table 1. Multivariate logistic linear regression of risk factors for Oesophagus cancer

\begin{tabular}{|c|c|c|c|c|}
\hline Factors & \multicolumn{2}{|c|}{ Esophageal cancer condition } & \multirow[t]{2}{*}{ COR (CI 95\%) } & \multirow[t]{2}{*}{ AOR (CI 95\%) } \\
\hline & Cases & Controls & & \\
\hline & Freq. $\%$ & Freq. $\%$ & & \\
\hline Age & & & & $1.031(0.577-1.842)$ \\
\hline $40-49$ & $6(15.4)$ & $42(42.4)$ & 1 & \\
\hline $50-59$ & $7(17.9)$ & $27(27.3)$ & $9.100(2.774-29.853) * *$ & $0.681(0.111-4.195)$ \\
\hline $60-69$ & $13(33.3)$ & $20(20.2)$ & $5.014(1.555-16.168)^{* *}$ & $0.976(0.160-5.970)$ \\
\hline $70+$ & $13(33.3)$ & $10(10.1)$ & $2.00(0.697-5.82)$ & $0.587(0.113-3.064)$ \\
\hline \multicolumn{2}{|c|}{ Oral hygiene (brushing teeth) } & & $0.396(0.252-0.621)^{* * *}$ & $1.089(0.559-2.122)$ \\
\hline Daily & $13(41.0)$ & $83(83.8)$ & & 1 \\
\hline
\end{tabular}


Texila International Journal of Public Health Special Edition Apr 2019

\begin{tabular}{|l|l|l|l|l|}
\hline Not daily & $23(59.0)$ & $16(16.2)$ & & $0.612(0.185-0.021)$ \\
\hline Alcohol consumption & & & \\
\hline No & $10(25.6)$ & $71(71.7)$ & 1 & 1 \\
\hline Yes & $29(74.4)$ & $28(28.3)$ & $13.96(5.268-36.924)^{* * *}$ & $8.76(2.40-32.0)^{* * *}$ \\
\hline Tobacco use & & & & \\
\hline No & $2480.0)$ & $93(93.9)$ & 1 & 1 \\
\hline Yes & $15(13.9)$ & $6(6.1)$ & $24.800(8.698-70.708)^{* * *}$ & $14.7(3.4-63.8)^{* * *}$ \\
\hline Fertilizer use & & & & \\
\hline No & $20(51.3)$ & $24(75.8)$ & 1 & 1 \\
\hline Yes & $19(48.7)$ & $75(24.2)$ & $0.304(0.140-0.662)^{* *}$ & $0.594(0.163-2.05)$ \\
\hline Aflatoxins & & & & 1 \\
\hline No & $30(76.9)$ & $43(43.4)$ & 1 & $1.12(0.35-4.10)$ \\
\hline Yes & $9(23.1)$ & $56(56.6)$ & $0.230(0.099-0.536)^{* *}$ & \\
\hline Pesticides & & & & 1 \\
\hline No & $24(61.4)$ & $69(69.7)$ & 1 & $0.83(0.23-3.10)$ \\
\hline Yes & $15(38.6)$ & $30(30.3)$ & $0.272(0.125-0.590)^{* *}$ & \\
\hline H. Pylori & & & & 1 \\
\hline No & $19(48.7)$ & $78(78.9)$ & 1 & $7.18(1.94-26.52)^{* *}$ \\
\hline Yes & $20(51.3)$ & $21(21.1)$ & $3.910(1.772-8.627)^{* *}$ & \\
\hline
\end{tabular}

\section{Appendix 3}

Table 2. As ranked by the key informants

\begin{tabular}{|l|l|l|l|}
\hline \multicolumn{1}{|c|}{ Factors } & Freq. & & \% \\
\hline Gender & 06 & 60 & 3 \\
\hline Age & 04 & 40 & 5 \\
\hline Family history & 03 & 30 & 6 \\
\hline Religion & 01 & 10 & 8 \\
\hline Marital status & 0 & 0 & 9 \\
\hline Education level & 0 & 0 & 9 \\
\hline Occupation & 5 & 50 & 4 \\
\hline Tobacco use & 9 & 90 & 1 \\
\hline Alcohol consumption & 7 & 70 & 2 \\
\hline Oral hygiene & 0 & 0 & 9 \\
\hline Hot beverages & 3 & 30 & 6 \\
\hline Vegetables\& fruits & 3 & 30 & 6 \\
\hline Physical activity & 1 & 10 & 8 \\
\hline Income level & 2 & 20 & 7 \\
\hline H. Pylori infection & 0 & 0 & 9 \\
\hline HPV infection & 3 & 30 & 8 \\
\hline Fertilizer use & 3 & 30 & 8 \\
\hline $\begin{array}{l}\text { Exposure to } \\
\text { Aflatoxin }\end{array}$ & 7 & 70 & 2 \\
\hline Pesticide use & 6 & & 3 \\
\hline
\end{tabular}

1 = very important, $6=$ least important. 